\title{
Storm waves focusing and steepening in the Agulhas current: Satellite observations and modeling
}

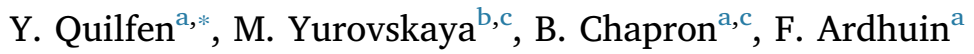 \\ a IFREMER, Univ. Brest, CNRS, IRD, Laboratoire d'Océanographie Physique et Spatiale (LOPS), Brest, France \\ ${ }^{\mathrm{b}}$ Marine Hydrophysical Institute RAS, Sebastopol, Russia \\ ${ }^{\mathrm{c}}$ Russian State Hydrometeorological University, Saint Petersburg, Russia
}

\section{A R T I C L E I N F O}

\section{Keywords:}

Extreme waves

Wave-current interactions

Satellite altimeter

SAR

\begin{abstract}
A B S T R A C T
Strong ocean currents can modify the height and shape of ocean waves, possibly causing extreme sea states in particular conditions. The risk of extreme waves is a known hazard in the shipping routes crossing some of the main current systems. Modeling surface current interactions in standard wave numerical models is an active area of research that benefits from the increased availability and accuracy of satellite observations. We report a typical case of a swell system propagating in the Agulhas current, using wind and sea state measurements from several satellites, jointly with state of the art analytical and numerical modeling of wave-current interactions. In particular, Synthetic Aperture Radar and altimeter measurements are used to show the evolution of the swell train and resulting local extreme waves. A ray tracing analysis shows that the significant wave height variability at scales $<\sim 100 \mathrm{~km}$ is well associated with the current vorticity patterns. Predictions of the WAVEWATCH III numerical model in a version that accounts for wave-current interactions are consistent with observations, although their effects are still under-predicted in the present configuration. From altimeter measurements, very large significant wave height gradients are shown to be well captured, and also associated with the current vorticity patterns at global scale.
\end{abstract}

\section{Introduction}

Severe sea states are encountered in the vicinity of storm tracks with extreme values of significant wave height (Hs) driven by the stormy winds and associated fetch length and duration (e. g. Hanafin et al., 2012). Extreme sea states not necessarily generated by local winds can also occasionally be found in some regions. Indeed, interactions between waves and currents induce change in the wave direction (Kenyon, 1971; Smith, 1976; Dysthe, 2001; Gallet and Young, 2014) and energy (Ardhuin et al., 2017; Kudryavtsev et al., 2017). For reference, the refraction of waves over random currents leading to the formation of rogue waves has been discussed in White and Fornberg (1998). Spatial wave height variations at scales $<\sim 100 \mathrm{~km}$ are then very often associated with current variability at the same scales.

Rogue or freak waves have been particularly recorded in the Agulhas current system (Mallory, 1974; Lavrenov, 1998). Although numerical wave models are capable to represent such effects (Holthuijsen and Tolman, 1991), the use of ocean currents in operational wave forecasting has been mostly applied to tidal currents (e.g. Ardhuin et al., 2012). Indeed, a key limitation of wave-current forecasting in the global ocean is the apparent inadequate combination of surface currents that are probably too coarse or not well positioned in space or time. When using resolutions of the order of $2 \mathrm{~km}$ for both current forcing and wave model implementation, the variability of modeled waves becomes indeed more consistent with observations in the range where these are available (Ardhuin et al., 2017).

From a satellite perspective, altimeters can provide robust measurements of the local significant wave height, sea surface roughness, and sea surface height, currently used to validate ocean numerical models for wave heights, mean sea level and eddy kinetic energy (Quilfen et al., 2000; Feng et al., 2006; Stopa et al., 2016). Continuous improvements in sensor technology and processing help to reduce measurements noise and open perspectives to analyze mesoscale variability $(20 \mathrm{~km}<\mathrm{L}<80 \mathrm{~km})$. Altimeter sea state measurements are further complemented by Synthetic Aperture Radar (SAR) with estimates of swell wave spectra and to help more precisely monitor swell propagation (e.g. Chapron et al., 2001; Collard et al., 2005; Ardhuin et al., 2009; Collard et al., 2009).

This potential gives the motivation for the present study to efficiently merge SAR directional measurements and swell propagation

\footnotetext{
* Corresponding author at: IFREMER, BP70, 29280 Plouzané, France.

E-mail address: Yves.Quilfen@ifremer.fr (Y. Quilfen).
} 
characteristics with altimeter sea state information. A case is analyzed using satellite altimeter and SAR measurements with numerical modeling, to highlight the main role of currents in focusing storm waves generated in the South Atlantic Ocean and propagating into the Agulhas current system. The analyzed case study is particularly well sampled by SAR and altimeter measurements, which are, for our case, very well synchronized in time to enable precise space-time tracking of the impinging swell system in the Agulhas current region. This region is known for frequent occurrence of extreme waves and is a challenging one for wave forecasting. The Agulhas Current is a strong western boundary current flowing poleward along the east coast of Africa from $27^{\circ} \mathrm{S}$ to $40^{\circ} \mathrm{S}$. The sources of the Agulhas Current are the East Madagascar Current, the Mozambique Current and a re-circulated part of the south-west Indian sub-gyre south of Madagascar. Large-scale cyclonic meanders are formed as the Agulhas Current reaches the continental shelf on the South African east-coast. In the south-east Atlantic Ocean the current turns back on itself in the Agulhas Retroflection and becomes the Agulhas Return Current meandering and flowing eastward to rejoin the Indian Ocean Gyre. Many eddies populate the Agulhas current area. A view of the Agulhas stream is shown on Fig. 4 at our case study time, and the interested reader may refer to Lutjeharms (2006) for a thorough description of this major current system. Unlike other western boundary currents (Brazil Current, Gulf Stream, and Kuroshio) it is exposed to strong westerly surface waves in the retroflection region.

Section 2 describes the storm case study, Section 4 describes the WAVEWATCH III numerical model experiment and the satellite data used, Section 5 presents the methods applied for altimeter data processing and swell rays calculation, Section 6 presents results in four main sub-sections: 1 ) the description and modeling of the incident swell trajectories after refraction and advection by the surface currents, 2) the analysis of wave energy transformation along the swell path using altimeter measurements and modeling results, 3) a discussion on potential errors likely to affect the proposed analysis, 4) a global statistical analysis that shows a ubiquitous relationship between large sea state gradients and surface current vorticity, probably associated with more frequent extreme waves (both in height and shape). Section 6 contains a summary of the results and discussion.

\section{Case study: Storm description}

A low pressure system developed off the Argentina coast near $60^{\circ} \mathrm{W} /$ $40^{\circ} \mathrm{S}$ on 24 February 2016 . Then it propagated eastward and merged with the circumpolar jet stream while strengthening. It reached its maximum intensity at about $30 \mathrm{~m} / \mathrm{s}$ on the 26th, with a translation velocity near $16 \mathrm{~m} / \mathrm{s}$. The storm intensity decreased slightly on the 27th while it crossed the zero meridian, then south of the Cape of Good Hope early on the 28th, and dissipated a few days later. Fig. 1 shows the wind field at times near the maximum intensity, obtained by the European Center for Medium range Weather Forecasting (ECMWF) numerical model $\left(0.125^{\circ}\right.$ resolution) and by the Advanced Microwave Scanning Radiometer 2 (AMSR-2). Different radiometers (Soil Moisture Active Passive, Windsat, AMSR-2) give estimates consistently higher than the ECMWF ones. The Meteorological Operational (Metop) Advanced SCATterometer (ASCAT) -A and -B gave values in line with the ECMWF winds, as expected since scatterometer winds are assimilated into the numerical model. Differences with radiometer measurements are consistent with previous results (Reul et al., 2017; Zabolotskikh et al., 2016). It can be explained 1) by the inherent smoothing performed by the numerical model, although its grid resolution is quite fine, 2) because sensitivity of actual scatterometers dramatically decrease for winds getting close to $30 \mathrm{~m} / \mathrm{s}$ and beyond (e.g. Quilfen et al., 2010; Mouche et al., 2017), and measurements can be biased with wave age (Quilfen et al., 2004), 3) and finally because both ECMWF model and scatterometer wind sources are strongly correlated (Pineau-Guillou et al., 2018). Radiometer winds are not assimilated into the ECMWF model, but their sensitivity to high winds, beyond $30 \mathrm{~m} / \mathrm{s}$, has often been reported (Quilfen et al., 2007; Reul et al., 2012). Yet, accurate calibration of the satellite data should be performed using a recognized reference source, which is still a matter of debate. In the frame of the present study, we make the hypothesis that the ECMWF maximum winds are underestimated, to possibly impact the WAVEWATCH III model results.

Size of the storm also matters as it determines the fetch conditions, together with the wind intensity and the translation speed. Size and translation speed are at least as important as maximum winds to constrain the wave field and its main characteristics: significant wave height and peak wavelength (Hanafin et al., 2012; Kudryavtsev et al., 2015). Storm size estimates from satellite sensors and ECMWF numerical model, often referenced as the $17 \mathrm{~m} / \mathrm{s}$ wind radius, are certainly defined with better accuracy than maximum winds. For our case study, ECMWF and satellite storm size estimates are indeed in very good agreement up to $20 \mathrm{~m} / \mathrm{s}$ radius, with above gale-force $(17 \mathrm{~m} / \mathrm{s})$ winds covering an area of about $4.10^{5} \mathrm{~km}^{2}$.

\section{Model and observations}

\subsection{WAVEWATCH III model runs}

The numerical model hindcasts were obtained on a quasi-global grid, with a resolution of $1 / 6^{\circ}$ in latitude $\left(48^{\circ} \mathrm{S}\right.$ to $\left.47^{\circ} \mathrm{N}\right)$ and longitude $\left(28^{\circ} \mathrm{W}\right.$ to $\left.57^{\circ} \mathrm{E}\right)$. The general numerical model framework is described by the WAVEWATCH III development group (2016). The particular settings used here follow from Rascle and Ardhuin (2013), with the addition of a $1 / 6^{\circ}$ two-way nested zoom around southern Africa, with a southern boundary at $48^{\circ} \mathrm{S}$. These model nests use third-order schemes with garden-sprinkler correction, and sub-grid island and iceberg blocking. The parameterizations combine the Discrete Interaction Approximation (Hasselmann et al., 1985), a wind-wave generation term adapted from Janssen (1991), [see Ardhuin et al., 2010 for the adjustment details], and dissipation parameterizations (Ardhuin et al., 2010). The model uses 24 directions and 32 frequencies $(0.037-0.72 \mathrm{~Hz})$. In the case presented here, the hindcast was run from 25 February 2016 until 29 February 2016, with an output grid every $3 \mathrm{~h}$. Forcing was provided by ECMWF analysis winds and by the Globcurrent daily geostrophic current components (http://www. globcurrent.org). These surface current fields are estimated on a $1 / 4^{\circ}$ resolution grid from sea surface height (SSH) measurements performed by several operational altimeters and using an optimal interpolation method (Ducet et al., 2000).

\subsection{Observations sources}

Ocean Surface Topography Mission (OSTM)/Jason-2 is a follow-on altimetric mission to the TOPEX/Poseidon and Jason-1 missions. The Jason- 2 altimeter operates at two frequencies $(13.6 \mathrm{GHz}$ in the Ku band, $5.3 \mathrm{GHz}$ in the $\mathrm{C}$ band) to determine ionospheric electron content, which affects the radar signal path delay. The altimeter performs measurements at nadir at about $6 \mathrm{~km}$ ground sampling along the satellite track. The Geophysical Data Records (GDR) used in this study are processed at Aviso center in Toulouse under the responsibility of the Centre National d'Etudes Spatiales (CNES) and the National Aeronautics and Space Administration (NASA).

The European Space Agency Sentinel-1 (S1) mission carries a SAR operating at C-band, which offers medium and high resolution imaging capabilities in all weather conditions. SAR Wave mode acquires data in $20 \mathrm{~km}$ by $20 \mathrm{~km}$ vignettes, at $5 \mathrm{~m}$ by $5 \mathrm{~m}$ spatial resolution, every $100 \mathrm{~km}$ along the orbit, acquired alternately on two different incidence angles. Vignettes on the same incidence angle are separated by $200 \mathrm{~km}$. Swaths alternate incidence angles between near range and far range $\left(23^{\circ}\right.$ and $36.5^{\circ}$ incidence angle, respectively).

The Advanced Microwave Sounding Radiometer 2 (AMSR-2) is a 

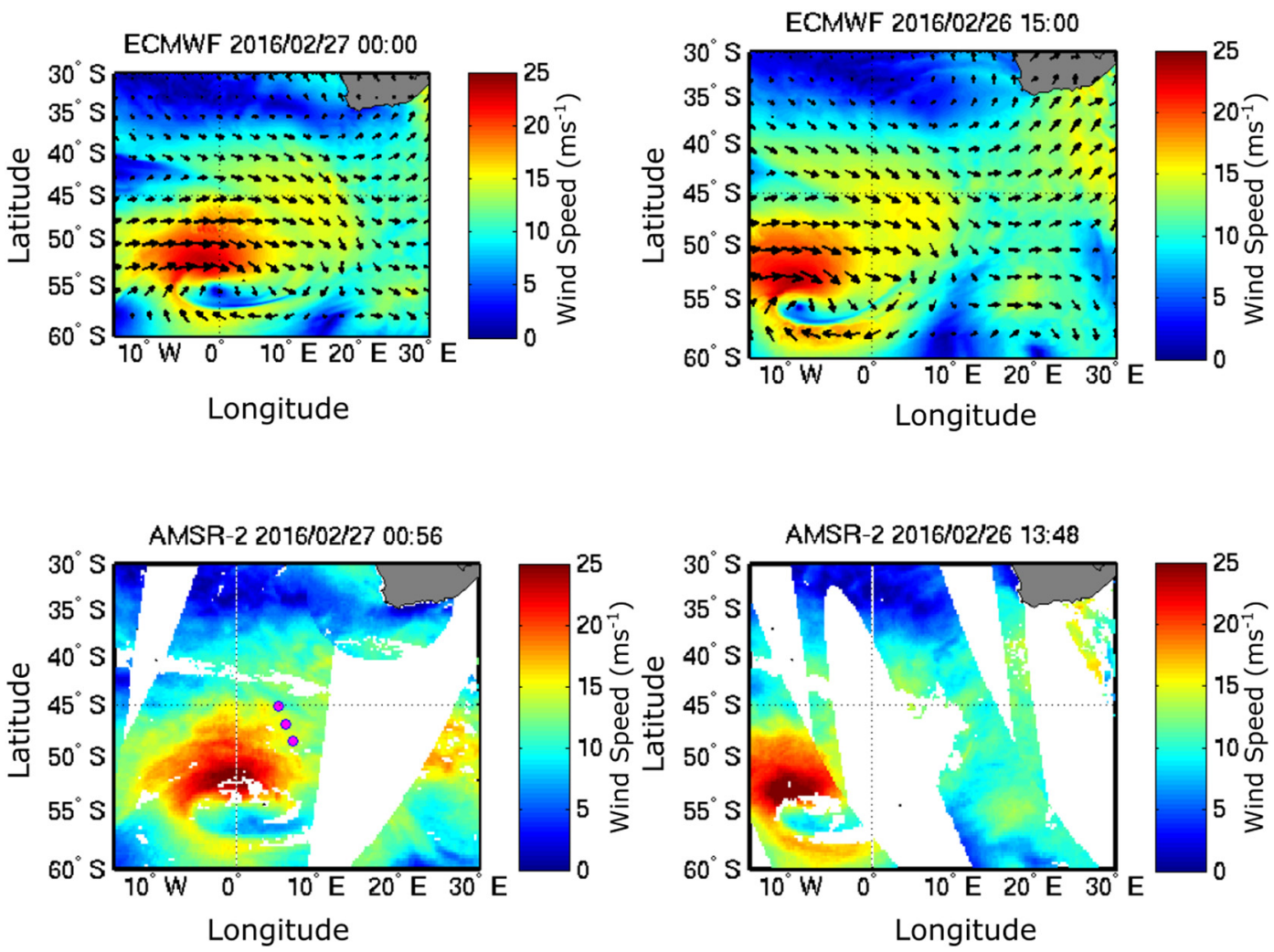


circles (bottom left panel) give the Sentinel-1 wave-mode images location across which the waves travel towards the Agulhas current system.

passive microwave radiometer, enabling estimation of wind speeds from brightness temperature of the oceans. It is operated on-board the Global Change Observation Mission-Water1 satellite since 2012. AMSR2 winds are provided by SOLab (Satellite Oceanography Laboratory, Russian State Hydrometeorological University). The wind product used in this study is Level 2, ungridded, with a spatial sampling of $10 \mathrm{~km}$.

The Advanced SCATterometer (ASCAT) is a real aperture radar, to enable estimate of wind speed and direction from backscatter coefficients. It is carried on-board the Meteorological Operational (Metop) polar satellites, launched by the European Space Agency (ESA) and operated by EUMETSAT (EUropean organisation for the exploitation of METeorological SATellites). Metop-A was launched in 2006, Metop-B in 2012. ASCAT $12.5 \mathrm{~km}$ spatial resolution wind products used in this study are provided by KNMI (Royal Netherlands Meteorological Institute, http://projects.knmi.nl/scatterometer/).

\subsection{Global wave field and satellite wave observations}

Fig. 2, left, shows the data used to describe the large scale wave field and its evolution approaching the Agulhas current system. The background field, colored image and arrows, traces the WAVEWATCH III model peak wavelength magnitude and direction, 24-h before the wave front arrived in the Agulhas current region. The time, 2016.02.27 18Z, matches the S1 satellite crossing at 18:36. Three S1 SAR wave-mode images are selected to provide directional information for the swells which propagate towards the Agulhas current system. The outlined envelope path is obtained by tracking forward the swell system refracted by surface currents, as explained in the next section. Four other S1 images are shown, Fig. 2 right, recorded the day after at 17:40. The corresponding WAVEWATCH III peak wavelength field gives the location of the swell system front. For these seven S1 images located as magenta circles in Fig. 2, a spectral analysis of the modulated radar cross section provides the swell wavelength and direction. A neural network algorithm provides a SAR estimate of Hs (Stopa and Mouche, 2017). Two Jason-2 altimeter tracks are also displayed. The first one, a descending track (aiming NE-SW) crossing the four eastern-most S1 wave-mode images, nearly aligns with the swell direction and gives an accurate instantaneous record of the Hs profile across the front of the incoming swell. Acquisition time of this altimeter track, 2016.02.28 $12: 46$, corresponds to the time just before the swell front entered in the Agulhas current system, about $5 \mathrm{~h}$ before the time of the WAVEWATCH III field shown in Fig. 2b (WAVEWATCH III field the closest to the S1 wave-mode images time). The second altimeter ascending track (aiming SE-NW) intersected the Agulhas current the day after, 2016.02.29 at 03:17, near the area where the swells are apparently shown to converge in the Fig. $2 \mathrm{a}$ and b. At this time, and as predicted by the WAVEWATCH III model (not shown), the swell front has already passed beyond this area towards South Africa.

\section{Methods}

\subsection{EMD-based de-noising process}

Current altimeter data give robust measurements of Hs, but retrieved values can be very noisy at the sensor ground sampling. One main source of noise comes from the altimeter waveform retracking algorithm, in addition to the instrumental noise (Sandwell and Smith, 2005; Thibaut et al., 2010). This issue can be mitigated by using suitable de-noising techniques. We use the Empirical Mode Decomposition (EMD; Huang et al., 1998; Kopsinis and McLaughlin, 2009), and techniques inspired by standard wavelet thresholding but with enhanced performance. In this approach, altimeter data are filtered out for the high resolution noise in the time domain, rather than in the frequency domain as in wavelet thresholding. It is then expected that geophysical information can be retrieved at scales $<\sim 80 \mathrm{~km}$. The EMD is applied to continuous $1 \mathrm{~Hz}$ data segments of at least $2^{6}$ data points (along-track 

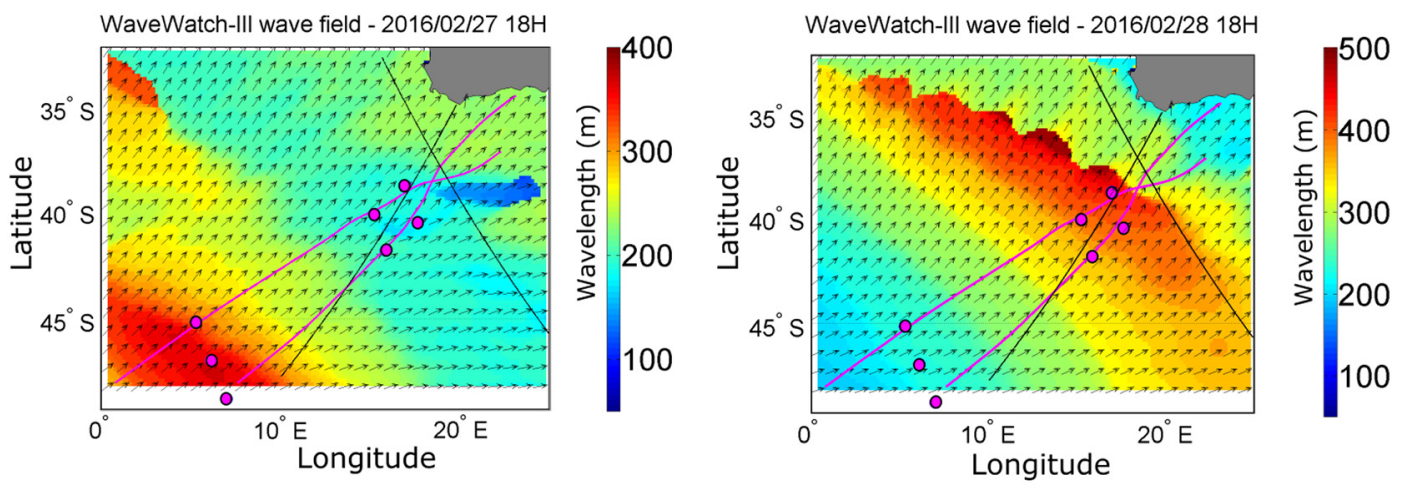

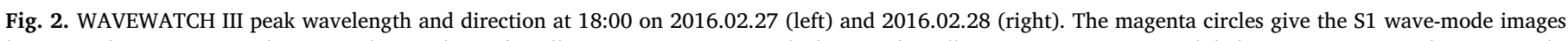

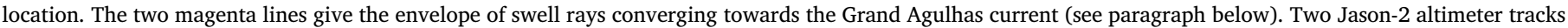
used in the study are shown as black solid lines.

length of about $450 \mathrm{~km}$ ). Each data segment is processed independently and the signal is decomposed in Intrinsic Modulation Functions (IMF) which are time functions modulated in amplitude and frequency. The process ranks, by construction, the IMFs from the one containing the highest frequencies to the latest containing the trend. Different techniques can then be used to characterize and filter the noise (Kopsinis and McLaughlin, 2009). Here the noise level is estimated from the first IMF and we use the Clear Iterative Interval Thresholding developed to account for the hypothesis that this first IMF is likely to contain some signal portions as well. The strength of this adaptive method is that the noise characteristics are objectively estimated from the data, making it particularly relevant to our data set that combines measurements from different altimeters with different noise characteristics. It preserves the meso- and sub-meso scale geophysical signal, unlike filtering methods generally applied to along-track $1 \mathrm{~Hz}$ data that either performs a lowfrequency cut-off or performs a time record smoothing that filters both the noise and the geophysical signal.

\subsection{Swell rays and energy transformation calculation}

Different processes operate that explain the wave spectrum evolution in presence of currents. The main ones are: 1) the refraction of waves which is related to the ratio of the current gradient (vorticity) to the wave group velocity; 2) the advection of wave action by the current vector; 3) a change in wavenumber and group speed; 4) the local influence of the wind vector relatively to the current vector. The relative contribution of each of them has been estimated and discussed in Ardhuin et al. (2017). It was estimated that the refraction and advection terms are the main contributors to the variance in Hs gradients at scale $<\sim 30 \mathrm{~km}$ and that, at scales $<\sim 20 \mathrm{~km}$, the terms 3) and 4) contribute to a larger Hs variance. These results have been obtained with WAVEWATCH-III forced with currents from the Regional Ocean Modeling System (ROMS) model at $1.5 \mathrm{~km}$ resolution. For our analysis, scales $<\sim 15 \mathrm{~km}$ are not resolved in the relatively low resolution altimeter measurements. Several other studies showed that refraction and advection are the main processes that contribute to wave transformation by currents (Smith, 1976; Irvine and Tilley, 1988; White and Fornberg, 1998; Lavrenov and Porubov, 2006; Gallet and Young, 2014).

Modeling of the propagation and transformation of a swell train through a variable current field can be done as described in Dysthe (2001) or Kudryavtsev et al. (2017). The main assumption is that the swell does not dissipate during the time it travels through the current system (time scaling). It is also assumed that the current itself is time independent during the swell propagation. Equations of the wave train evolution can be written as follows:

$d \boldsymbol{x} / \mathrm{dt}=\frac{\partial \Omega}{\partial \boldsymbol{k}}$ $d \boldsymbol{k} / \mathrm{dt}=-\frac{\partial \Omega}{\partial \boldsymbol{x}}$

$\mathrm{dN} / \mathrm{dt}=0$

where $\Omega(\boldsymbol{k}, \boldsymbol{x})=\sqrt{\mathrm{gk}}+\boldsymbol{k} \cdot \boldsymbol{u}$ is the dispersion function and $N(\boldsymbol{k})=\mathrm{E}(\boldsymbol{k}) / \sqrt{\mathrm{gk}}$ is the wave action. $\boldsymbol{k}$ is the wave vector and $\boldsymbol{u}$ is the surface current vector. Bold characters denote vectors.

From the two first equations and above given assumptions, it can be derived (see Kenyon, 1971; and Eq. (7) in Dysthe, 2001) a revealing formula showing that refraction of gravity waves by current gradients can be quantified by:

$\vartheta=\frac{\xi}{C g}$ where $\vartheta$ is the ray curvature, $\xi$ is the current vorticity, and $\mathrm{Cg}$ is the wave group velocity. The ray curvature is proportional to the current vorticity and inversely proportional to the wave group velocity. A consequence is that, in case of irrotational currents, the ray paths remain almost as straight lines. Schematics of the refraction process can be found in Gallet and Young (2014) or in White and Fornberg (1998).

A forward ray-tracing is done by solving for the two first equations iteratively in time, to give the swell trajectories, i.e. rays $x$, and the wave number $k$ along the trajectory. In this numerical scheme, the refraction, advection, and wavenumber change processes are accounted for. The incoming swell is specified by its wavenumber and direction of propagation at the entrance of the domain.

To estimate the transformed two-dimensional spectrum in every point of the domain, a backward ray-tracing technique is used. For each ray of the forward ray-tracing, with wavenumber $\mathrm{k}_{\mathrm{i}}$ and direction $\varphi_{\mathrm{i}}$ on a spectrum grid with a step $\mathrm{dk}=10^{-3} \mathrm{rad} / \mathrm{m}$ and $\mathrm{d} \varphi=1^{\circ}$, the backtime evolution is computed until the ray crosses the line with the specified spectrum $\mathrm{E}_{0}$, where its wavenumber $\mathrm{k}_{\mathrm{j}}$ and direction $\varphi_{\mathrm{j}}$ have been fixed. Values of wave action spectrum $\mathrm{E}_{0}\left(\mathrm{k}_{\mathrm{j}}, \varphi_{\mathrm{j}}\right) / \Omega\left(\mathrm{k}_{\mathrm{j}}, \varphi_{\mathrm{j}}\right)$ is assigned to $\mathrm{E}\left(\mathrm{k}_{\mathrm{i}}, \varphi_{\mathrm{i}}\right) / \Omega\left(\mathrm{k}_{\mathrm{i}}, \varphi_{\mathrm{i}}\right)$, accordingly to the wave action conservation law. After performing such a procedure at every grid point, one obtains the total energy spectrum in a given coordinate. Integration of the spectrum and comparing it with the integral of $\mathrm{E}_{0}$ gives the estimation of wave energy intensification/attenuation after wave train evolution. The 2-D energy spectrum of the incoming swell Eo is specified as a gaussian function, constant at the boundary of the domain where the swell enters, with specified width parameters $\left(\Delta \mathrm{k} / k_{p} ; \Delta \Phi\right)$ (see Kudryavtsev et al., 2017 for more details).

\section{Results}

5.1. Refraction and advection of the incident swell system by the surface current

5.1.1. Initial conditions for the incident swell system from SAR observations

For our case study, the incident waves can be characterized, in the far field away from the Agulhas current region, using the SAR wave- 
Table 1

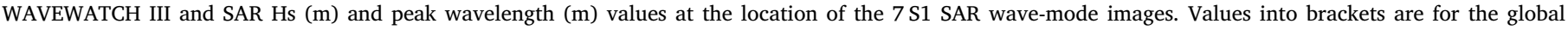
WAVEWATCH III model at $0.5^{\circ}$ resolution.

\begin{tabular}{|c|c|c|c|c|c|c|c|}
\hline Position (incidence angle) & 40.1S/15.2E (23.3) & $38.8 \mathrm{~S} / 17.0 \mathrm{E}(36.4)$ & 40.5S/17.6E (36.3) & 41.9S/15.9E (23.3) & $46.8 \mathrm{~S} / 6.1 \mathrm{E}(36.2)$ & $45.1 \mathrm{~S} / 5.3 \mathrm{E}(36.2)$ & $48.5 \mathrm{~S} / 7.0 \mathrm{E}(36.1)$ \\
\hline Date & 2016.02 .28 & 2016.02 .28 & 2016.02 .28 & 2016.02 .28 & 2016.02 .27 & 2016.02 .27 & 2016.02 .27 \\
\hline Time & $17: 40: 31$ & $17: 40: 46$ & $17: 40: 16$ & $17: 40: 02$ & $18: 36: 04$ & $18: 36: 34$ & $18: 35: 35$ \\
\hline $\begin{array}{l}\text { Hs WAVEWATCH III } \\
\text { 18:00:00 }\end{array}$ & $5.2(4.9)$ & $4.9(4.7)$ & $5.1(5.1)$ & $5.0(5.0)$ & $7.7(7.8)$ & $6.5(6.4)$ & $(7.8)$ \\
\hline $\begin{array}{l}\text { Lp WAVEWATCH III } \\
\text { 18:00:00 }\end{array}$ & 393 (393) & $434(406)$ & 393 (393) & $358(358)$ & $358(358)$ & $319(301)$ & $(348)$ \\
\hline Hs/NN S1 & 5.8 & 4.7 & 5.3 & 5.1 & 7.5 & 6.5 & 8.3 \\
\hline Lp S1 & 425 & 497 & 491 & 390 & 460 & 316 & 419 \\
\hline
\end{tabular}

mode images shown in the southwest part, Fig. 2. As WAVEWATCH III model results for swell parameters are known to be less accurate than for the wind sea (Ardhuin and Coauthors, 2010; Stopa et al., 2016), the incident swell characteristics have been taken from the SAR images peak wavelength and Hs estimates. Table 1 summarizes these estimates for the seven wave-mode images shown in Fig. 2, and the corresponding WAVEWATCH III values at the synoptic time the closest to the SAR images time.

The Hs values are in overall agreement between observations and the WAVEWATCH III model, although the model peak wavelength is significantly underestimated in most cases. As the time difference between the model and the SAR data is small, one may conclude that the model systematically underestimates the peak wavelength. There is a significant variation in the peak wavelength between the three southwest wave-mode images, in agreement with the WAVEWATCH III field, showing that the central wave-mode image is located in the area where the model also locates the maximum wavelengths. We therefore hypothesize that the central wave-mode image sampled the waves in the front of the swell system, with a peak wavelength of about $460 \mathrm{~m}$.

After the time of this $\mathrm{S} 1$ pass, the storm was in a decreasing stage, had traveled east of the S1 track, and was not likely to further feed the swell system towards the Agulhas current.

Fig. 3 shows the sea surface roughness image (left) and the derived wave spectrum (right) for the wave-mode image selected above. Surface waves generated by the storm are clearly revealed traveling with an azimuth of $50^{\circ}$ clockwise relatively to the north and a peak wavelength of $460 \mathrm{~m}$. At the synoptic time near the wave-mode image time, the WAVEWATCH III model gives a value of $358 \mathrm{~m}$ at the wave-mode image location and a maximum value of $380 \mathrm{~m}$.



5.1.2. Incident swell system trajectory: Rays tracing and satellite observations

The trajectory of the incoming swell through the Agulhas current system is computed using the ray tracing analysis and mapped to illustrate refraction effects. For our particular storm case study of an incoming swell with $460 \mathrm{~m}$ peak wavelength and an incoming angle of $50^{\circ}$ relatively to the north, the waves are traveling with a group velocity of $<\sim 13 \mathrm{~m} / \mathrm{s}$ in a current field with maximum speed values near $2 \mathrm{~m} /$ $\mathrm{s}$. To leading order, the direction of propagation will be deflected by an angle $\theta=\xi l / C g$ with $\xi$ surface current gradient (vorticity), 1 distance and $C g$ the group velocity. To quantify, a swell traveling over a distance of $200 \mathrm{~km}$ in a current with a mean vorticity of $2 \mathrm{e}^{-5} \mathrm{~s}^{-1}$ (as calculated from the Globcurrent field) will be deflected by an angle of $17^{\circ}$. Fig. 4 illustrates numerical solutions of the kinematic equations to show that the incoming swell rays, going through the four wave-mode images, are focusing in the Agulhas current flowing in the direction opposite to the swell. Interestingly, it is also the location where the ascending Jason-2 altimeter track intersected the Agulhas current.

The SAR images of sea surface roughness and associated wave spectra are presented in Fig. 5, for the two northernmost wave-mode products that lie nearly along the same swell ray. Located at distinct areas in the Agulhas current system, sea surface roughness images are quite different. Regular patterns are imaged for the westernmost measurements of the swell train entering into the current system, while the other exhibits swell perturbations (SAR acquisition farther in the Agulhas current). The wave spectrum reports for these differences, with a multi-modal spectrum reflecting some directional spreading for the later image. A 5-degrees difference between the direction of the two most energetic modes can be associated with swell direction perturbations by the current, as shown in Fig. 4. Differences in peak wavelength among the four SAR wave-mode images recorded on 28 17:40



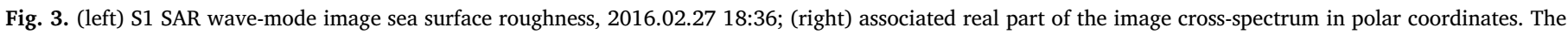

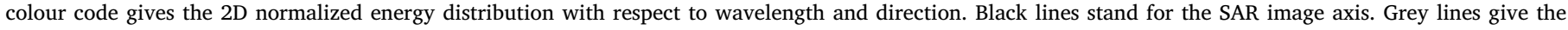

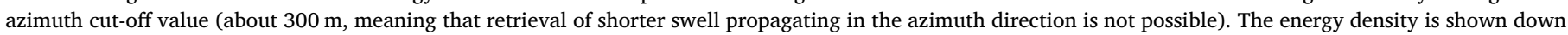

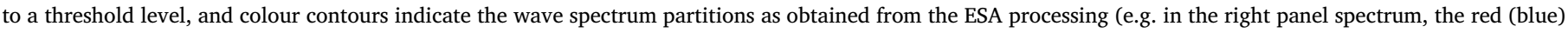

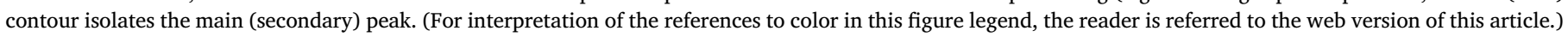




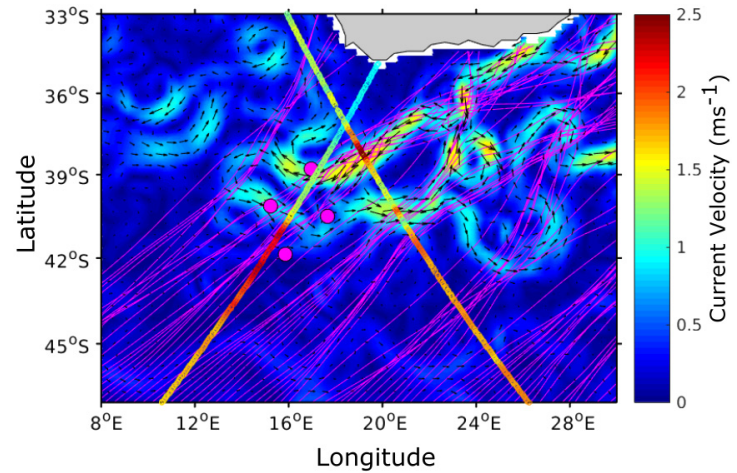

Fig. 4. Daily surface geostrophic currents, 2016.02.28 (velocity as black arrows). The magenta lines map the swell rays. The magenta circles give the S1 wave-mode images location the same day. Two Jason-2 altimeter tracks are shown, whose Hs values are normalized to fit the current scale.

are consistent with the global picture of the wavelength field given by WAVEWATCH III (Fig. 2, right panel), although model values are systematically lower. The S1 images give a maximum measured at $497 \mathrm{~m}$ for the northeast image (Fig. 5, left panel) and a minimum measured at $390 \mathrm{~m}$ for the southwest image, while the northwest and southeast images give $425 \mathrm{~m}$ and $491 \mathrm{~m}$, respectively.

To better interpret the wave-mode images features and for reference, the Fig. 6 shows the ASCAT-b scatterometer wind field at 19:57 on 28 th. The $0.5 \mathrm{~m} / \mathrm{s}$ isoline of surface current is also shown as a black solid line. It indicates that the wind vector field was almost perpendicular to the swell direction near the SAR wave-mode images. The wind field was opposing the surface current in the northern branch of the Agulhas and was flowing with the current in the southern branch. No clear wind sea signature appears in the image spectra, although the lower sea surface roughness in the northeast corner in Fig. 5, right image, can be associated with the area of lower wind speed in the northeast of the wave-mode images area as shown in Fig. 6.

At the time of the S1 pass, 17:40, it would take $9 \mathrm{~h}$ to a swell system with $390 \mathrm{~m}$ wavelength and $12.4 \mathrm{~m} / \mathrm{s}$ group velocity to travel the



Fig. 6. ASCAT-b scatterometer wind speed and direction (black arrows) on 2016.02.28 19:57. The magenta circles give the S1 wave-mode images location. The black solid line gives the $0.5 \mathrm{~m}$ /s contour line of the Globcurrent surface currents the same day. The current directions are given in Fig. 4.

$400 \mathrm{~km}$ along a ray separating the southwest SAR image from the Jason-2 altimeter ascending track intersecting the Agulhas current the day after at 03:17. It almost perfectly corresponds to the altimeter pass time with a registered $9 \mathrm{~m}$ Hs peak as the altimeter track crossed the main current. As shown in Fig. 2, right panel, the main swell front had crossed beyond the S1 images area at their time, 28th 17:40, and had also crossed beyond the Jason- 2 ascending pass at the altimeter time, 29th 03:17. SAR and altimeter observations thus likely did not record the most extreme sea states associated with this particular event traveling through the Agulhas current system.

In the following section, altimeter data are further analyzed in combination with wave-current interactions modeling, to illustrate and analyze the interactions between the incident swell and the Agulhas current.
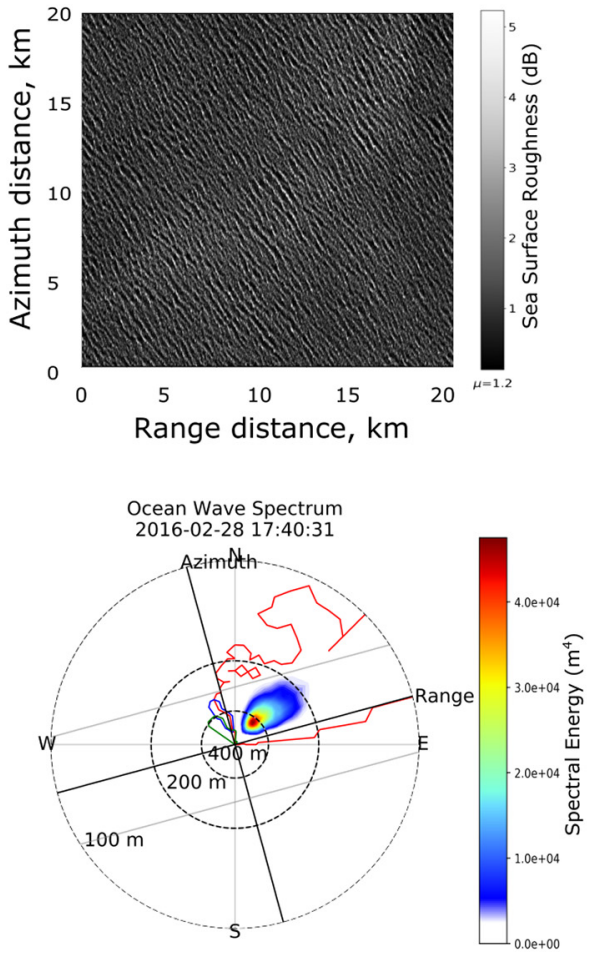


Fig. 5. (top) Sea surface roughness for the two northernmost S1 wave-mode images (left: western, right: eastern), 2016.02.28 17:40; (bottom) associated real part of the image cross-spectrum in polar coordinates. The colour code gives the $2 \mathrm{D}$ normalized energy distribution with respect to wavelength and direction. Black lines stand for the SAR image axis. Grey lines give the azimuth cut-off value (about $300 \mathrm{~m}$, meaning that retrieval of shorter wave in the azimuth direction is spurious). The energy density is shown down to a threshold level, and colour contours indicate the swell partitions as obtained from the ESA processing (e.g. in the right spectrum, the red (blue) contour isolates the main (secondary) peak). (For interpretation of the references to color in this figure legend, the reader is referred to the web version of this article.) 



Fig. 7. Top: WAVEWATCH III peak wavelength on 28th, 12:00, and re-scaled altimeter Hs at 12:46 (cycle 282, orbit 31 ) as a function of latitude. Location of S1 wave-mode images is shown as magenta circles. Bottom: Jason-2 (blue) and WAVEWATCH III (black) Hs (left axis), and Jason-2 sigma0 (right axis), along the Jason-2 track. The solid (dashed) black line shows the WAVEWATCH III Hs output with (without) current forcing.

\subsection{Wave energy transformation}

\subsubsection{Altimeter observations of wave energy transformation}

The Jason-2 altimeter pass crossed the main swell front on February 28th, 12:46, just before the front entered in the Agulhas current system. The Fig. 7 , top, shows that the swell front shape, as depicted by the WAVEWATCH III peak wavelength field at 12:00, is in good agreement with the altimeter Hs gradient. WAVEWATCH III maximum wavelength of about $500 \mathrm{~m}$ is predicted in the west part. Altimeter Hs values in the swell front reach $7 \mathrm{~m}$, Fig. 7 bottom, and the altimeter radar cross section (sigma0) evolution shows that the Hs gradient in the front is not associated with a change in the local wind. Although its resolution is 1/ $6^{\circ}$, the WAVEWATCH III model underestimates values of Hs magnitude and gradient. Both the altimeter and the model show a plateau (e.g. Hs $\sim 4 \mathrm{~m}$ ) ahead of the front corresponding to the forerunner waves.

For the second Jason-2 altimeter track, crossing the Agulhas current at 03:17 the day after, Fig. 9, top, shows that the main swell front already crossed beyond the altimeter track. The altimeter recorded Hs


Fig. 9. Same as Fig. 7 but on 29th, 03:00 for WAVEWATCH III and 03:17 for Jason-2 altimeter (cycle 282, orbit 48).

values above $8 \mathrm{~m}$, (e.g. Fig. 10), with gradients up to $1.5 \mathrm{~m}$ over $10 \mathrm{~km}$. These gradients are not linked to the wind, Fig. 8, right, and the small decrease in the altimeter radar cross section (Fig. 9 bottom), anti-correlated with the Hs peak, is likely associated to increased sea surface roughness by both anomalously high sea state and wind/current opposing effects as shown in Fig. 6. Previous section results showing the focusing of swell rays (Fig. 4), explain these extreme waves with both the effects of interactions of swells focusing and trapping in the current and interaction of swell opposing the surface current.

The Hs predicted by the WAVEWATCH III model with the current forcing are highly smoothed, but accounting for surface currents undoubtedly improves the results in a very encouraging way by comparison to hindcasts without current forcing. The larger Hs peak is predicted by the model, but interestingly the smaller observed Hs variability between $40^{\circ} \mathrm{S}$ and $42^{\circ} \mathrm{S}$ is also tenuously reproduced. It shows that the physical processes at play in the numerical model can reproduce the observed variability, although the WAVEWATCH III predicted swell direction apparently does not show the clear focusing patterns as observed in Fig. 4. With higher spectral resolution and/or better spatial resolution of the current forcing field, the WAVEWATCH III results should better converge to the ray-tracing result. As outlined
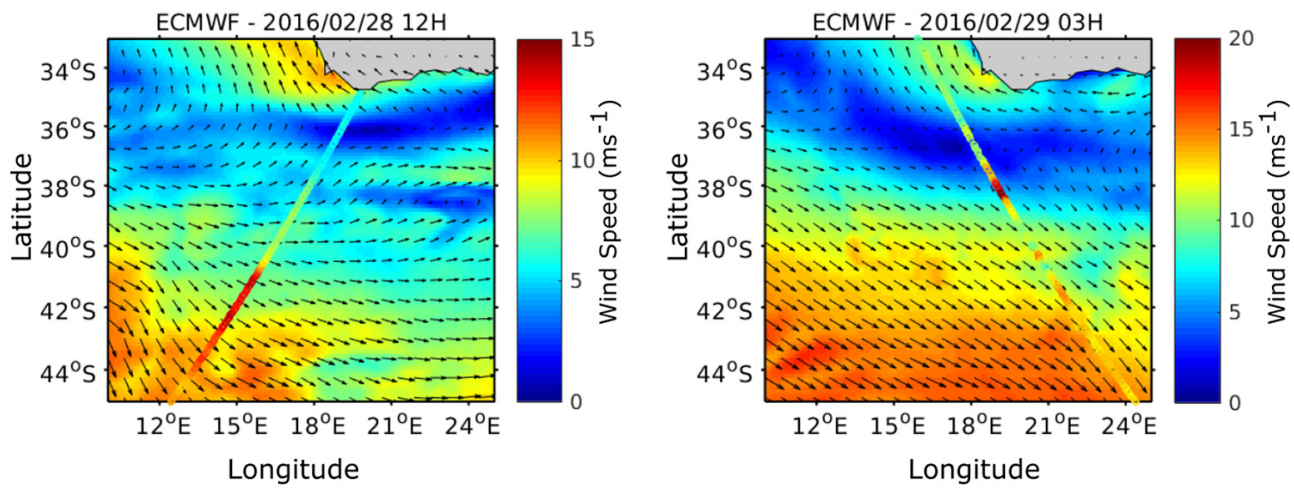


to fit the wind scale. 

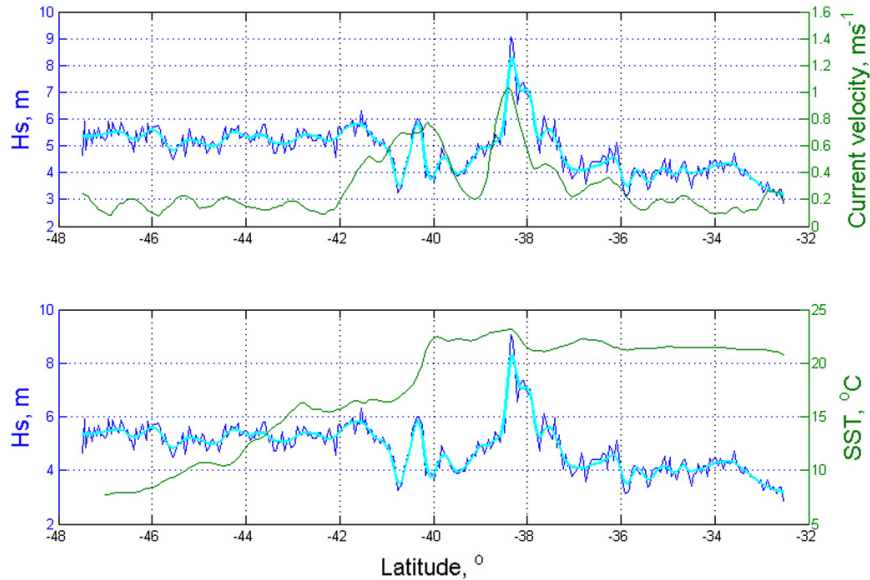

Fig. 10. Raw (blue solid line) and filtered (cyan solid line) Jason-2 Hs (left axis) on 29th, 03:17, and Globcurrent daily geostrophic velocity the same day (top, right axis), and Odyssea daily SST the same day (bottom, right axis).

in Section 2, the ECMWF winds are also likely underestimated to impact the WAVEWATCH III results in such a way.

Fig. 10 displays, along the same altimeter track shown in Fig. 9, the variability of the Hs together with the interpolated geostrophic current speed and sea surface temperature (SST). Aside the main $\sim 9 \mathrm{~m} \mathrm{Hs} \mathrm{peak}$ located in the westward Agulhas current, the secondary peak at $40.5^{\circ} \mathrm{S}$ appears to be associated with the other Agulhas branch flowing eastward and collocated with a large SST front. As shown in Fig. 4, the location of the secondary peak is also an area where rays are converging and areas on both sides are ray density "holes" associated with lower sea states. The higher sea states on the south of the current system are from the background wind sea state generated by local winds as shown in Fig. 8 (right panel). We then obtain a consistent description from the combined analysis of altimeter measurements and rays tracing obtained from swell refraction modeling.

\subsubsection{Modeling of wave energy transformation}

Altimeter measurements can be further analyzed and compared to wave energy transformation estimated using the backward ray-tracing described in Section 4.2. Total energy $E$ is computed at each altimeter data point along the Jason-2 ascending orbit. Initial peak wavenumber and direction values used for ray calculation, i.e. $460 \mathrm{~m}$ peak wavelength and incoming angle of $50^{\circ}$, are estimated from SAR spectrum (Fig. 3). As the spectral width parameters cannot always be reliably estimated from SAR data, different cases are considered by varying the standard deviation of the Gaussian spectrum: a narrow spectrum $(\Delta \mathrm{k} /$ $\left.k_{p}=0.2 ; \Delta \Phi=10^{\circ}\right)$, a 'medium' spectrum $\left(\Delta \mathrm{k} / k_{p}=0.4 ; \Delta \Phi=15^{\circ}\right)$, and a wide spectrum $\left(\Delta \mathrm{k} / k_{p}=0.7 ; \Delta \Phi=30^{\circ}\right)$ cases. As observed from SAR, Fig. 3, the well-defined swell system would rather pertain to the narrow or medium cases. WAVEWATCH III model results at $10^{\circ} \mathrm{E}$ and $48^{\circ} \mathrm{S}$ give a directional spread of $18^{\circ}$ at the peak of the storm. Yet, this number should be considered with caution given the relatively large errors for that parameter (Stopa et al., 2016).

Results are presented Fig. 11, to show, along the altimeter track, the scaled Hs measurements compared to $\sqrt{E / E_{0}}$. As expected, narrower is the spectrum, larger is the increase in wave energy along the altimeter transect. This is particularly found at the location where the swell rays converge in the Agulhas branch opposing the swell. The ray tracing model predictions thus reproduce well the measured increase in wave energy in the main branch of the eastward Agulhas current (with decreased wavelength, not shown). Results also show three secondary maxima/minima (with increased wavelength, not shown), but shifted along the altimeter track. These secondary variations in wave energy are presumably associated with areas where swells are converging/diverging, Fig. 4. Indeed, rays converge in the westward Agulhas branch,

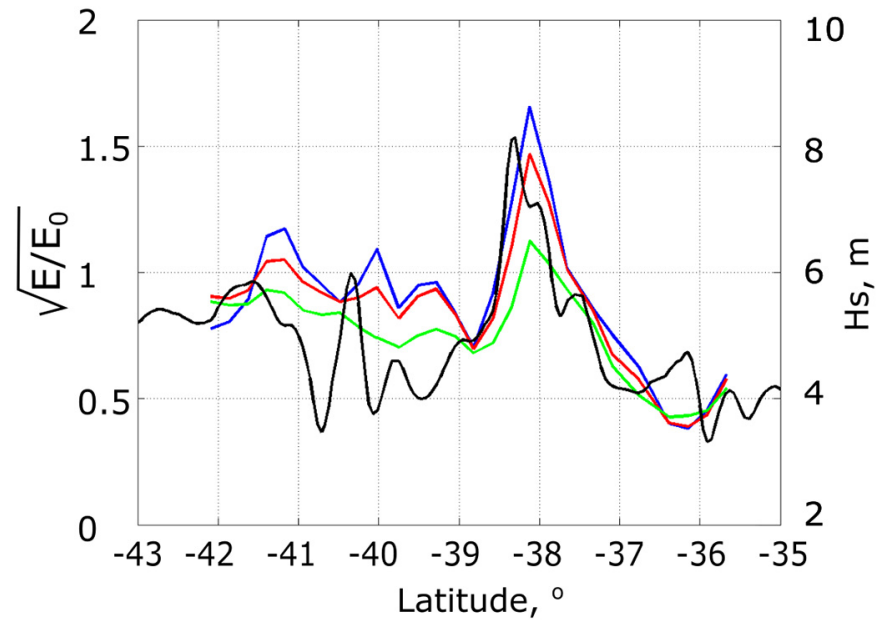

Fig. 11. Jason-2 Hs (right axis, black solid line) on 29th, 03:17, and the energy enhancement factor (left axis) calculated along the altimeter track for three spectrum widths; blue: $\Delta \mathrm{k} / k_{p}=0.2 ; \Delta \Phi=10^{\circ}$; red: $\Delta \mathrm{k} / k_{p}=0.4 ; \Delta \Phi=15^{\circ}$; green: $\Delta \mathrm{k} / k_{p}=0.7 ; \Delta \Phi=30^{\circ}$. (For interpretation of the references to color in this figure legend, the reader is referred to the web version of this article.)

but also in its eastward branch where swell refraction is likely to be also determined by the Agulhas current rings. To note, if local currents are clearly the cause of local energy focusing (as for the north branch of the Agulhas), the computed wave energy change is also the result of integrated effects along the whole swell path and correlation with local surface current gradients may then be not so apparent locally.

\subsection{Discussion}

Previous section gives a description of the transformation of a swell system in the Agulhas current. Models and observations are consistent although differences are observed for the following reasons.

First, the incident swell characteristics were chosen from one single SAR image located near the swell front system. However, these values of wave number and direction can vary slightly along the swell front as shown in the WAVEWATCH III wavelength field, Fig. 2 left. This may sufficiently modify rays of the incoming swell system to give significant differences in location of the modeled and measured wave energy transformation, Fig. 4 and Fig. 11 (see also Fig. 4 of Kudryavtsev et al., 2017). Another possible limitation of our analysis is that only contribution of refraction and wave action advection are considered, including change in wavenumber. Although these processes are generally dominant (Ardhuin et al., 2017), the adjustment of local atmospheric forcing to the current, that influences the wind sea part of the spectrum and contributes to changes in significant wave heights, is not taken into account.

Second, the daily geostrophic surface current field can be subject to limitations in its space/time representativeness, to impact ray tracing and WAVEWATCH III predictions. Indeed, small changes in the current field can lead to a substantial change in the wave trajectories (Irvine and Tilley, 1988). The use of mean daily currents makes sense because the characteristic time of current variability is much larger than the wave propagation time. More critical, the relatively coarse, $1 / 4$ degree spatial resolution, can give a current field (and related gradients) smoother than the truth, to significantly impact the results since wave trajectories are shown to be very sensitive to the current gradient and curvature. Further, current patterns might be not correctly located.

To exemplify the potential error sources in our particular case, the Fig. 12 gives the noise and variability patterns associated with the along-track altimeter measurements of Hs and sea level anomalies (SLA, used to estimate the geostrophic current).

The top panel shows the raw (blue line, $1 \mathrm{~Hz}$ values) $\mathrm{Hs}$ 

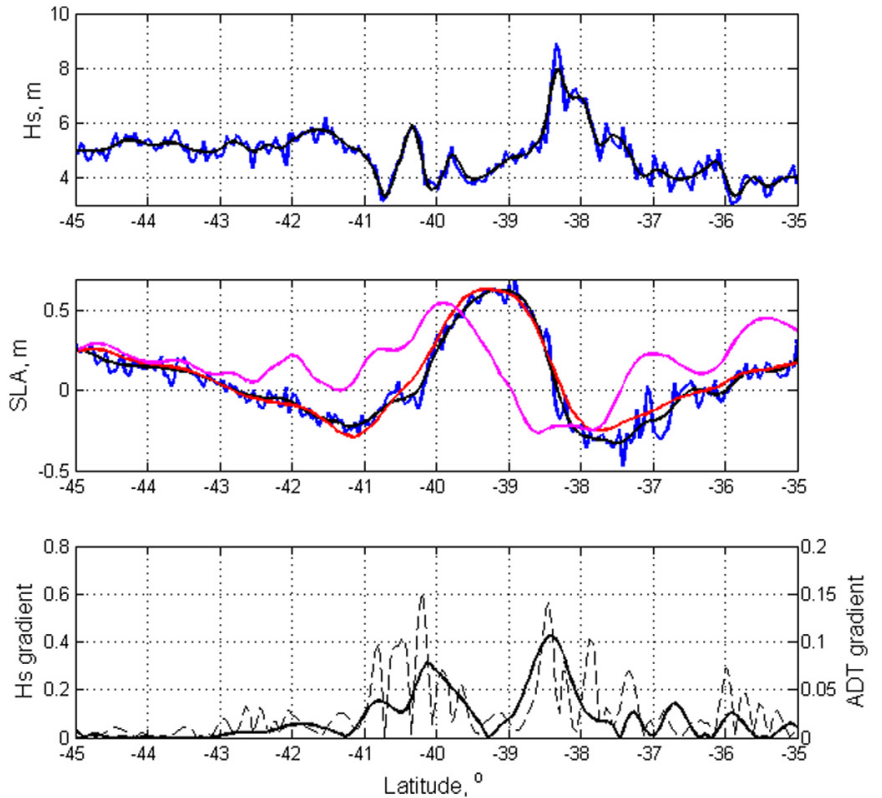

Fig. 12. Jason-2 Hs, SLA, and ADT on 29th, 03:17. Top panel: Hs raw (blue) and filtered (black) values; middle panel: Jason-2 raw (blue) and filtered (black) SLA values, and altimeter mean daily SLA field $\left(1 / 4^{\circ} \times 1 / 4^{\circ}\right)$ spatially interpolated (red), and Mercator model hourly SLA field $\left(1 / 12^{\circ} \times 1 / 12^{\circ}\right)$ spatially interpolated (magenta); bottom panel: absolute values of Hs (dashed) and ADT (solid) gradients. measurements and the EMD's filtered values (black line).

Displayed on the middle panel are the along track Jason-2 SLA's estimates on 29th $03: 17$, compared with the multi-altimeter mean daily SLA field (red line, used to compute the Globcurrent field) and with the Mercator numerical model hourly SLA field (magenta line, $1 / 12^{\circ}$ spatial resolution). It shows few differences between the altimeter SLA on 29th 03:17 and the mean daily SLA, giving confidence that the daily averaged Globcurrent field did not smooth too much the current variability or shift the surface patterns. However it also shows that $1 / 4^{\circ}$ resolution does not fully resolve the mesoscale vorticity and that the computation based on Globcurrent field may likely underestimate wave-current interactions. The Mercator model at $1 / 12^{\circ}$ resolution shows significantly larger spatial variability, but a large shift in the location of the maximum of SLA also reflects a shift in the location of the Agulhas current main patterns. The ray tracing analysis using the Mercator current fields then does not give realistic results (not shown).

As shown on upper panels of Fig. 12, EMD denoising of Hs and absolute dynamic topography (ADT $=$ SLA + mean topography) measurements leaves an along track signal whose gradients are shown on the lower panel. The two wide peaks near $-38.5^{\circ} \mathrm{S}$ and $-40.2^{\circ} \mathrm{S}$ are coincident with the two main branches of the Agulhas current. It shows that Hs variability at scales less than about $100 \mathrm{~km}$ is related to the current patterns, although a strong local correlation is not necessarily expected because observed Hs gradients may be the result of current effects integrated all along the swell path and because local wind forcing is also likely to contribute to the Hs variability as well. The most salient feature is that the largest absolute values of the Hs gradients are associated with the Agulhas current branches. To best illustrate this
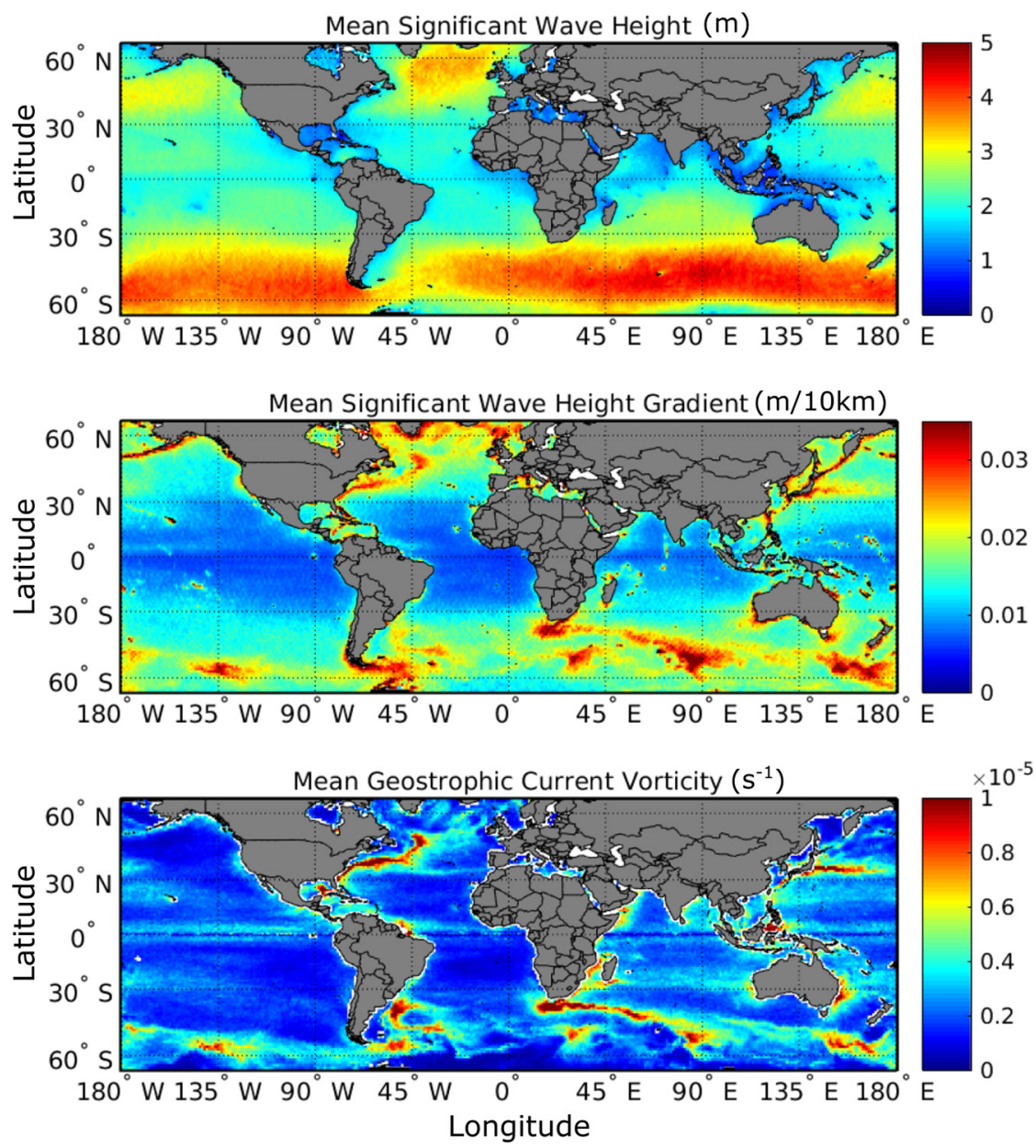

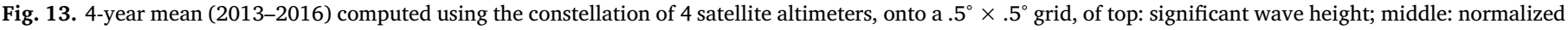
gradient of significant wave height; bottom: absolute value of surface current vorticity. 
result, a climatological analysis of the Hs gradient is discussed in the following section.

\subsection{Characterization of wave/current interactions at global scale}

Current altimeter data give robust measurements of Hs, but retrieved values can be subject to large noise at the sensor ground sampling. As already discussed, EMD-based denoising techniques (Kopsinis and McLaughlin, 2009) can be used to efficiently map the Hs variability at scales $<\sim 100 \mathrm{~km}$. Thanks to effective reduction noise, the Hs derivative can be systematically computed along track at the scale of the altimeter ground sampling, before averaging to obtain climatological gridded values. This mapping benefits from the amount of global data provided by 4 altimeters operational during the time period covering the years 2013 to 2016 .

Fig. 13 displays the 4-year mean values of the Hs, normalized alongtrack Hs gradient, and surface current vorticity onto a $.5^{\circ} \times .5^{\circ}$ grid. It shows that Hs gradients are systematically enhanced in areas where surface current vorticity is larger, at the boundaries of the main currents (e. g. Agulhas and Kuroshio currents) and in regions with energetic mesoscale and submesoscale variability (e.g. Drake Passage). The present case study highlighted the correlation between the Hs variability and the surface current vorticity patterns; Fig. 13 shows that this also clearly applies at global scale. In the Agulhas current system, the climatological distribution of waves (not shown) is largely weighted by storm waves coming from the southern ocean, to give the well characterized statistical signature of wave-current interactions, as shown in Fig. 13.

For different regimes of ocean circulation and waves, one may relate simply the observed Hs gradient signature to the current gradient. Indeed, considering a 1-D situation, i.e. waves encountering a current gradient along their propagation path, and considering the wave group velocity much larger than the surface current, the wave action conservation, Eq. (3) in Section 4.2, simplifies to $H s / \omega=C t e$. With $\nabla \omega \simeq \omega \nabla U / C g$, it gives $\nabla H s \simeq \frac{1}{2} H s \nabla U / C g$, with $U$ the surface current and $\mathrm{Cg}$ the wave group velocity. This is in quantitative agreement with the spectral analysis performed by Ardhuin et al. (2017), see their Eq. (9), who also suggested that the small-scale variability of wave heights is mostly governed by current variability. They analyzed different case studies showing increased Hs gradients in the Gulf Stream and the Drake Passage, areas clearly highlighted in the Fig. 13, showing larger climatological values of the normalized Hs gradient. The above suggested relation also relates the Hs gradient to the wave group velocity: shorter the waves, larger the wave-current interaction and induced Hs gradient. Differences in wave conditions thus explain part of the differences shown in Fig. 13 between the Hs normalized gradient and the current patterns. Moreover, in the 2-D physical space, Hs gradients will further be dramatically enhanced in caustics where rays focusing leads to wave energy concentration.

Finer analysis of these statistics, and associated annual or year to year variability, can thus certainly be investigated through the mean of an altimeter constellation from various space agencies and will be the subject of further studies. Accurate estimates of altimeter Hs and gradient measurements at scale $<\sim 30 \mathrm{~km}$, possibly combined with radar cross section roughness measurements (Rascle et al., 2014), is certainly a step forward to open new tracks for surface current variability observations.

\section{Summary}

A case study combining satellite data and numerical modeling is investigated to analyze the track of a particular storm wave system and its evolution through the Agulhas current. The study benefits from state of art numerical wave modeling and relies upon the availability of an ensemble of altimeter and SAR observations in a fortunate very favourable configuration for this case study. Indeed, times of the satellite passes combine well to enable tracking of this swell system through the Agulhas current region. Wave-current interactions increase variability of the significant wave height field at scales $<\sim 100 \mathrm{~km}$. At such scales, altimeter measurements can be heavily corrupted by noise. Denoising is therefore a necessary step before analyzing data and it is an outcome of the study to show that the Empirical Mode Decomposition approach performs well and is critical to infer the results shown in Fig. 13.

Swell focusing is exemplified as solutions of the kinematic equations describing the refraction of a swell train by surface currents. Predicted locations of the focusing swells in caustics, and expected wave energy increase, agree with the localized extreme waves recorded by the Jason2 altimeter in the Agulhas current. The main patterns of the Hs mesoscale variability are shown to be correlated with the surface current vorticity. Realistic high resolution numerical wave model simulations using a specific WAWEWATCH III configuration and integrating the surface current forcing, show improvement over the wind only forcing, to corroborate observations concerning the main role of surface currents in Hs variability at scale $<\sim 100 \mathrm{~km}$. However, the magnitude of wave height variability is significantly under-predicted by the model, and finding avenues for improvement is an exciting ongoing challenge. One issue of the study concerns the choice and accuracy of the surface currents used to model the wave-current interactions. For the present case study, the Mercator model sea level anomalies show too large differences with altimeter observations to enable use of the numerical model currents in the present analysis. Mean daily altimeter geostrophic current fields have been used in our modeling experiments, but their rather coarse resolution may translate in underestimation of the current vorticity and derived WAVEWATCH III sea state variability. Use of geostrophic currents rather than total currents is done because no satellite direct measurements of the total current are available yet. However, it does not change the results since the Ekman component of the current is shown to be weak in this case.

As derived from altimeter measurements, large Hs gradients are associated with the wave system interacting with surface currents, with extreme values of about $1.5 \mathrm{~m}$ over $10 \mathrm{~km}$. An altimeter-derived global statistical description of wave height gradients is further presented to show this ubiquitous relationship with surface currents. A global map of $\mathrm{Hs}$, Hs gradient, and surface geostrophic current vorticity is shown in Fig. 13. The data used to map the mean fields are altimeter along track data averaged on a $1 / 2^{\circ}$ grid. The shown mean Hs gradient is obtained by averaging gradients and is then not equivalent to the mean gradient that would be calculated from the mean Hs field. The later gradients are much smaller and then do not show up in the mean gradient field shown in Fig. 13. Accordingly, this study highlights that the climatological areas of maximum Hs gradients are not primarily related to the main sea state and wind patterns, but to the main current patterns.

Such results open new perspectives to combine higher resolution wide-swath SAR and delay-doppler altimeter measurements for a better understanding and mapping of wave-current interactions Kudryavtsev et al., 2012, and to improve extreme sea state predictions and monitoring. Further progress will also certainly benefit from coming satellite missions such as Surface Water and Ocean Topography (SWOT) and Chinese-French Oceanic SATellite (CFOSAT), or from the foreseen Sea surface KInematics Multiscale (SKIM) mission. These satellites will carry innovative sensors dedicated to surface currents and sea state measurements.

\section{Acknowledgements}

This study was conducted within the Ocean Surface Topography Science Team (OSTST) activities. OSTST is led by CNES and NASA and a grant was awarded by the TOSCA board to the ORPHEO (Observation, Research, extreme PHEnomena over the Oceans) project in the frame of the CNES/EUMETSAT call CNES-DSP/OT 12-2118. One co-author was granted by the Russian Science Foundation, grant 17-77-30019. The authors acknowledge use of data from the European Space Agency 


\section{GlobCurrent project.}

\section{References}

Ardhuin, F., Coauthors, 2010. Semi-empirical dissipation source functions for wind-wave models: part I, definition, calibration and validation. J. Phys. Oceanogr. 40, 1917-1941. https://doi.org/10.1175/2010JPO4324.1.

Ardhuin, F., Coauthors, 2012. Numerical wave modeling in conditions with strong currents: dissipation refraction, and relative wind. J. Phys. Oceanogr. 42, 2101-2120. https://doi.org/10.1175/JPO-D-11-0220.1.

Ardhuin, F., Chapron, B., Collard, F., 2009. Observation of swell dissipation across oceans. Geophys. Res. Lett. 36. https://doi.org/10.1029/2008GL037030.

Ardhuin, F., Gille, S.T., Menemenlis, D., Rocha, C.B., Rascle, N., Chapron, B., Gula, J., Molemaker, J., 2017. Small-scale open-ocean currents have large effects on windwave heights. J. Geophys. Res. Oceans 122, 4500-4517. https://doi.org/10.1029/ 2016JC012413.

Chapron, B., Johnsen, H., Garello, R., 2001. Wave and wind retrieval from SAR images of the ocean. Ann. Telecommun. 56 (11-12), 682-699.

Collard, F., Ardhuin, F., Chapron, B., 2005. Extraction of coastal ocean wave fields from SAR images. IEEE J. Ocean. Eng. 30. https://doi.org/10.1109/JOE.2005.857503.

Collard, F., Ardhuin, F., Chapron, B., 2009. Monitoring and analysis of ocean swell fields from space: new methods for routine observations. J. Geophys. Res. 114. https://doi. org/10.1029/2008JC005215.

Ducet, N., le Traon, P.Y., Reverdin, G., 2000. Global high-resolution mapping of the ocean circulation from TOPEX/POSEIDON and ERS-1/2. J. Geophys. Res. 105 (19), 477-498.

Dysthe, K., 2001. Refraction of gravity waves by weak current gradients. J. Fluid Mech. 442, 157-159. https://doi.org/10.1017/S0022112001005237.

Feng, H., Vandermark, D., Quilfen, Y., Chapron, B., Beckley, B., 2006. Assessment of wind forcing impact on a global wind-wave model using TOPEX altimeter. Ocean Eng. 33 (11-12), 1431-1461.

Gallet, B., Young, W.R., 2014. Refraction of swell by surface currents. J. Mar. Res. 72 (2), $105-125$.

Hanafin, J.A., et al., 2012. Phenomenal sea states and swell from a North Atlantic storm in February 2011: a comprehensive analysis. Bull. Am. Meteorol. Soc. 93 (12), $1825-1832$.

Hasselmann, S., Hasselmann, K., Allender, J.H., Barnett, T.P., 1985. Computation and parameterizations of the nonlinear energy transfer in a gravity-wave spectrum. Part II: parameterizations of the nonlinear energy transfer for application in wave models. J. Phys. Oceanogr. 15, 1378-1391.

Holthuijsen, L.H., Tolman, H.L., 1991. Effects of the Gulf Stream on ocean waves. J. Geophys. Res. 96 (C7), 12755-12771.

Huang, N.E., et al., 1998. The empirical mode decomposition and the Hilbert spectrum for nonlinear and non-stationary time series analysis. Proc. R. Soc. Lond. 454, 903-993. https://doi.org/10.1098/rspa.1998.0193.

Irvine, D.E., Tilley, D.G., 1988. Ocean wave directional spectra and wave-current interaction in the Agulhas from the shuttle imaging radar-B synthetic aperture radar. J. Geophys. Res. 93, 15389-15401.

Janssen, P.A.E.M., 1991. Quasi-linear theory of wind-wave generation applied to wave forecasting. J. Phys. Oceanogr. 21, 1631-1642.

Kenyon, K.E., 1971. Wave refraction in ocean currents. Deep Sea Res. Oceanogr. Abstr. $18,1023-1034$.

Kopsinis, Y., McLaughlin, S., 2009. Development of EMD-based denoising methods inspired by wavelet thresholding. IEEE Trans. Signal Process. 57, 1351-1362.

Kudryavtsev, V., Myasoedov, A., Chapron, B., Johannessen, J.A., Collard, F., 2012. Imaging mesoscale upper ocean dynamics using synthetic aperture radar and optical data. J. Geophys. Res. 117. https://doi.org/10.1029/2011JC007492.

Kudryavtsev, V., Golubkin, P., Chapron, B., 2015. A simplified wave enhancement criterion for moving extreme events. J. Geophys. Res. Oceans 120 (11), 7538-7558. https://doi.org/10.1002/2015JC011284.

Kudryavtsev, V., Yurovskaya, M., Chapron, B., Collard, F., Donlon, C., 2017. Sun glitter imagery of surface waves. Part 2: waves transformation on ocean currents. J. Geophys. Res. Oceans 122, 1384-1399. https://doi.org/10.1002/2016JC012426.
Lavrenov, I., 1998. The wave energy concentration at the Agulhas current of South Africa. Nat. Hazards 17, 117-127.

Lavrenov, I.V., Porubov, A.V., 2006. Three reasons for freak wave generation in the nonuniform current. Eur. J. Mech. B. Fluids 25. https://doi.org/10.1016/j.euromechflu. 2006.02.009.

Lutjeharms, J.R.E., 2006. The Agulhas Current. Springer, Berlin.

Mallory, J.K., 1974. Abnormal waves in the south-east coast of South Africa. Int. Hydrogr. Rev. 51, 89-129.

Mouche, A., Chapron, B., Zhang, B., Husson, R., 2017. Combined co- and cross-polarized SAR measurements under extreme wind conditions. IEEE Trans. Geosci. Remote Sens. 99. https://doi.org/10.1109/TGRS20172732508.

Pineau-Guillou, L., Ardhuin, F., Bouin, M.N., Redelsperger, J.L., Chapron, B., Bidlot, J.R., Quilfen, Y., 2018. Strong winds in a coupled wave-atmosphere model during a North Atlantic storm event: evaluation against observations. Q. J. R. Meteorol. Soc. 44. https://doi.org/10.1002/qj.3205.

Quilfen, Y., Bentamy, A., Delecluse, P., Katsaros, K., Grima, N., 2000. Prediction of sea level anomalies using ocean circulation model forced by scatterometer wind and validation using TOPEX/Poseidon data. IEEE Trans. Geosci. Remote Sens. 38, 1871-1884.

Quilfen, Y., Chapron, B., Collard, F., Vandemark, D., 2004. Relationship between ERS scatterometer measurement and integrated wind and wave parameters. J. Atmos. Ocean. Technol. 21 (2), 368-373. https://doi.org/10.1175/1520-0426(2004)021.

Quilfen, Y., Prigent, C., Chapron, B., Mouche, A.A., Houti, N., 2007. The potential of QuikSCAT and WindSat observations for the estimation of sea surface wind vector under severe weather conditions. J. Geophys. Res. 112, C09023. https://doi.org/10. 1029/2007JC004163.

Quilfen, Y., Chapron, B., Tournadre, J., 2010. Satellite microwave surface observations in tropical cyclones. Mon. Weather Rev. 138, 421-437. https://doi.org/10.1175/ 2009MWR3040.1.

Rascle, N., Ardhuin, F., 2013. A global wave parameter database for geophysical applications. Part 2: model validation with improved source term parameterization. Ocean Model 70, 145-151. https://doi.org/10.1016/j.ocemod.2012.09.001.

Rascle, N., Chapron, B., Ponte, A., Ardhuin, F., Klein, P., 2014. Surface roughness imaging of currents shows divergence and strain in the wind direction. J. Phys. Oceanogr. 44, 2153-2163. https://doi.org/10.1175/JPO-D-13-0278.1.

Reul, N., Tenerelli, J., Chapron, B., Vandemark, D., Quilfen, Y., Kerr, Y., 2012. SMOS satellite L-band radiometer: A new capability for ocean surface remote sensing in hurricanes. J. Geophys. Res. 117, C02006. https://doi.org/10.1029/2011JC007474.

Reul, N., Chapron, B., Zabolotskikh, E., Donlon, C., Mouche, A., Tenerelli, J., Collard, F., Piolle, J.F., Fore, A., Yueh, S., Cotton, J., Francis, P., Quilfen, Y., Kudryavtsev, V., 2017. A new generation of Tropical Cyclone Size measurements from space. Bull. Am. Meteorol. Soc. 98. https://doi.org/10.1175/BAMS-D-15-00291.1.

Sandwell, D.T., Smith, W.H.F., 2005. Retracking ERS-1 altimeter waveforms for optimal gravity field recovery. Geophys. J. Int. 163, 79-89 (doi:101111/j.1365246X.2005.02724.x).

Smith, R., 1976. Giant waves. J. Fluid Mech. 77, 417-431.

Stopa, J.E., Mouche, A., 2017. Significant wave heights from Sentinel-1 SAR: Validation and applications. J. Geophys. Res. Oceans 122. https://doi.org/10.1002/ 2016JC012364.

Stopa, J., Ardhuin, F., Husson, R., Jiang, H., Chapron, B., Collard, F., 2016. Swell dissipation from 10 years of Envisat ASAR in wave mode. Geophys. Res. Lett. 43, 3423-3430. https://doi.org/10.1002/2015GL067566.

Thibaut, P., Poisson, J.C., Bronner, E., Picot, N., 2010. Relative performance of the MLE3 and MLE4 retracking algorithms on Jason-2 altimeter waveforms. Mar. Geod. 33, 317-335.

WAVEWATCH III development group, 2016. User manual and system documentation of WAVEWATCH III version 5.16. In: Tech. Note 329. NOAA/NWS/NCEP/MMAB, College Park, Md (326 pp.).

White, B.S., Fornberg, B., 1998. On the chance of freak waves at sea. J. Fluid Mech. 355, 113-138. https://doi.org/10.1017/S002211209700775.

Zabolotskikh, E.V., Reul, N., Chapron, B., 2016. Geophysical model function for the AMSR2 C-band wind excess emissivity at high winds. IEEE Geosci. Remote Sens. Lett. 13 (1), 78-81. 